\title{
CLÁUDIO, Mário. Ursamaior. Lisboa: Dom Quixote, 2000 (180 páginas).
}

Dalva Calvão Universidade Federal Fluminense

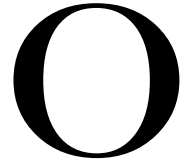

leitor que tem acompanhado o percurso ficcional de Mário Cláudio encontrará, neste seu último romance, alguns dos principais elementos que marcaram sua produção anterior, podendo atestar, mais uma vez, a coerência que atravessa a proposta de construção narrativa do autor de Amadeo. Assim, por exemplo, em Ursamaior, novamente nos deparamos com uma hábil indefinição de limites entre história e ficção, para a reconstrução do percurso de uma ou de várias vidas, confirmando a opção do escritor pelo relato biográfico, sempre percebido como estreita relação entre o real e o imaginado.

Entretanto, tais marcas comuns não serão, talvez, suficientes para evitar uma certa surpresa diante deste livro de Mário Cláudio, de tal forma o universo nele focalizado se distancia daqueles a que se dedicou o escritor em suas narrativas anteriores. Habituado a encontrar, em seus textos, a presença de figuras do mundo artístico ou histórico português (como Eça de Queirós, em As Batalhas do Caia, ou Vasco da Gama, em Peregrinação de Barnabé das Indias), ou de figuras que, sem a mesma dimensão histórica, identificam-se, contudo, com o universo social e familiar do próprio autor (como as personagens da Quinta das Virtudes ou de Tocata para dois clarins), possivelmente estranhará o leitor as personagens e o espaço que compõem o relato de 
Ursamaior, na verdade uma espécie de coletânea de relatos sobre personagens distantes dos modelos que a sociedade costuma eleger para seus possíveis homenageados, componentes de um grupo de excluídos que, sob a ótica mais comum, não mereceriam registros que preservassem suas histórias.

O núcleo narrativo de Ursamaior é a história de Henrique, universitário que mata a tiros sua namorada, em pleno corredor da Faculdade onde estudam. Baseado em um crime real que, em 1994, chocou a cidade do Porto, o relato sobre a vida de Henrique e sobre o assassinato por ele cometido mereceu cuidadosa pesquisa por parte de Mário Cláudio, que longamente teria entrevistado o verdadeiro criminoso na prisão, para, a partir de seus depoimentos, recriar, ficcionalmente, a verdade trágica por ele protagonizada. A freqüência ao ambiente carcerário teria, por outro lado, permitido ao autor o contato com vários outros presidiários, com base em cujas histórias ele constrói uma espécie de painel do universo marginalizado de uma prisão portuguesa, configurando um adequado pano de fundo para a história principal, aquela que gira em torno do crime mais grave e mais incompreensível, o assassinato da jovem estudante.

Desta forma, a história de Henrique é narrada em seis capítulos que, entre o instante exato do crime e a permanência final na prisão, apresentam variados momentos do passado da personagem, desde episódios de sua infância, até a realização do julgamento. Tais capítulos, em que, como em todos os outros, a voz narrativa ora se apresenta em primeira, ora em terceira pessoa, não se dispõem, contudo, de forma continuada: a cada episódio da vida de Henrique, intercala-se um capítulo sobre a vida, presente e passada, de cada uma das outras seis personagens: Gerardo, homem de negócios, bem nascido, que se transforma, ao longo da vida, em jogador compulsivo; Sérgio, policial acusado de violar uma mulher; Rogério, cabeleireiro e mestre em danças de salão que, fraudulentamente, adquire luxuoso automóvel; Cristiana, transformista, inadvertidamente envolvido em um assalto; Albino, prosaico dono de bar que se 
transforma em traficante de antigüidades, e Jorge, jovem garçon de uma pizzaria, seduzido pelo luxo, irresponsável participante de um roubo. No presente da narrativa, todas estas personagens habitam o mesmo espaço recluso, sem, entretanto, estabelecerem relações entre si ou efetuarem referências umas às outras - apenas Henrique será uma referência comum a quase todas que, em diferentes momentos e por variados motivos, registram seus contatos com o estudante ou expôem suas reflexões sobre ele.

Para além das personagens e do espaço inusitado, este livro apresenta ainda outra diferença em relação a quase toda a obra anterior de Mário Cláudio, cujas histórias se situam, preferencialmente, em épocas passadas, trazendo para o texto outras realidades históricas, sejam estas a sociedade portuguesa e européia do final do século XIX e início do século XX, como nos livros da Trilogia da mão, o país das perseguições aos judeus e das viagens marítimas do final do século XIV, recuperado na Peregrinação de Barnabé das Índias, ou o Portugal que se estende do período salazarista à Revolução de Abril, como vemos em Tocata para dois clarins. Em Ursamaior, o tempo evocado é o presente, a realidade de uma cidade portuguesa do final do século XX e princípios do século XXI, invadida pelos signos da globalização e do consumismo, dos modismos e da alienação, que tornam semelhantes todos os grandes centros urbanos ocidentais, descaracterizados em suas comuns perversões, ameaçados pelos mesmos fantasmas, sejam estes o vírus do HIV ou o consumo das drogas.

Chama, também, a atenção a variedade e a propriedade dos registros lingüísticos utilizados pelo escritor na composição deste romance, exigência certamente das características sociais e culturais de suas personagens, que, entretanto, acentuam, novamente, as diferenças em relação à produção antecedente. Sem que se percam as principais características da linguagem primorosamente trabalhada com que foram construídos seus outros romances, Mário Cláudio parece revelar, em Ursamaior, um alargamento de suas experiências com a palavra escrita, 
convocando, para seu texto, algumas vezes, construções próprias de diferentes jargões, vocabulário e expressões impensáveis em qualquer um dos romances anteriores, mas que, neste, garantem intenções de verossimilhança, sem que, por outro lado, interfiram na evidente elaboração e poeticidade do texto em seu conjunto.

Assim resumido, Ursamaior pode dar a impressão de se organizar, sobretudo, ou apenas, como um romance de franca intenção denunciatória, em que tanto seriam expostos os desmandos sociais que permitem ou facilitam a criminalidade, quanto os equívocos da instituição carcerária, suposto instrumento de recuperação que, na realidade, acaba por alimentar e reproduzir a violência que deveria combater, revelando-se, desta forma, como uma metonímia da organização social em que se insere, em nada contribuindo para o crescimento do indivíduo ali confinado. Este exercício de denúncia, certamente, pode ser depreendido da leitura do romance, conduzindo o leitor a reflexões sobre determinadas questões sociais contemporâ- neas, o que parece indiciar possíveis ampliações de rumos dentro da ficção do autor, voltado, neste momento, para sua própria época, preocupado em abordar, de forma explícita, as mazelas resultantes de uma engrenagem social contraditória e violenta, desigual e medíocre.

No entanto, para além de qualquer proposta denunciatória no sentido apontado acima, o que ressalta da leitura deste romance parece ser a intenção de expor e de buscar entender a complexidade interior de cada personagem, os secretos motivos que os levam aos delitos, os mais profundos sentimentos que sustentam os atos cometidos por cada um, figuras que escapam ao mero condicionamento social. Neste sentido, o que se percebe, na história de cada personagem, é um dominante sentimento de inquietação e de carência, a insatisfação com a própria vida, a angústia diante do vazio e do tédio e o desmando em busca de uma solução apaziguadora, sentimentos e atitudes muito anteriores à experiência carcerária, sendo, na verdade, os elementos aparentemente responsáveis pelos crimes cometidos. 
Não por acaso, o que se percebe, nas vivências de cada personagem, antes da prisão, é um desejo de evasão, a criação de um mundo paralelo, de uma outra verdade, de um outro jogo, que não o que são obrigados, limitadamente, a jogar: assim, os cassinos são, para o jogador compulsivo, o território da vertigem e do risco, a excitação que o retira do real e de suas conseqüências; para o cabeleireiro, as pistas e salões freqüentados nos concursos de dança abrem as perspectivas de um mundo de liberdade e de glamour, que apenas acentuam a pobreza de seu cotidiano; as peças antigas, em sua beleza e raridade, valorizadas ainda mais pelo risco das operações ilegais de aquisição e venda, libertam o contrabandista do tédio e da falta de alegria de sua atividade anterior de dono de bar. Caminhos semelhantes percorrem o transformista - seduzido pelo lado delicado, fútil e alegre do universo feminino, embriagado pelo brilho das fantasias e pela mágica ilusão de seus espetáculos teatrais - e o jovem vendedor de pizzas - deslumbrado participante da permanente e falsa euforia vivida por seus amigos ricos, que lhe concedem a extravagância de sua intimidade pontuada pela droga, devolvendo-o, depois, inconformado, ao cotidiano sem evasão. Talvez o único que não revele a si mesmo, de forma muito clara, sua interna insatisfação seja o policial: possivelmente o mais ambíguo de todos os companheiros de prisão, ele nega a violação sexual de que é acusado, mas revela, em suas reflexões, o comportamento preconceituoso e violento que sempre tivera com as mulheres, possível sintoma de sua intensa dificuldade interior. No entanto, ao invés de optar, como os outros, pela transgressão libertadora, ele faz, ao menos aparentemente, a opção pela ordem e pelo mando, realizando, no orgulho da farda, a satisfação narcísea de sua fantasia ignorada.

Sobre os motivos e sentimentos de todas as outras personagens, destacam-se, evidentemente, os de Henrique, dono da interioridade mais complexa, dominado pela angustiada necessidade de superação dos conflitos que, desde a infância, o 
atormentavam. Prisioneiro de sua própria confusão interior, acentuada a partir da obsessiva e mórbida relação amorosa com a colega universitária, Henrique pratica o crime como uma forma de libertação, julgando-se instrumento de alguma força misteriosa que, ao escolhê-lo, confere a ele uma espécie de superioridade. A morte da namorada é, assim, vista por ele, não como uma punição, mas como uma forma de purificação para ambos. Apaziguado e incompreendido, inteligente e culto, ele manterá uma desdenhosa distância em relação aos companheiros de prisão e a todo o ambiente carcerário, isolando-se em suas reflexões a respeito de si mesmo e do mundo, cada vez mais mergulhado no labirinto de sua interioridade, na lógica pessoal que construiu para, com clareza e calma, se explicar:

"Nenhum de nós representa apenas aquilo que é, mas também os infindáveis mundos donde veio. A prova está nos actos que não conseguimos justificar, mas que talvez exprimam a substância de que somos feitos" (p.97).

Em seu isolamento, Henrique marca de tal forma sua diferença que alguns companheiros relacionam suas atitudes à presença de demônios, justificando, desta forma, a força que o mantém e a frieza de seu crime:

"Eu pensava na situação de um rapaz chamado Henrique que lá cumpria uma pena de dezassete anos, e que corria ter sido possuído pelo Demónio, perguntando a mim mesmo se não me acontecera uma coisa parecida" (p.66).

Vemos, pois, que, por entre aquelas possivelmente originadas de uma construção social injusta e alienadora, avultam outras e mais misteriosas motivações para o comportamento das personagens desta trama, ocultas razões fundadas em terrenos mais profundos da subjetividade, enraizadas em frustrações pessoais e no próprio sentimento humano de desamparo e de perplexidade diante da insatisfação do real, o que nos remete a questões metafísicas universais e permanentes, redimensionadas pelo olhar crítico e pela palavra poética do autor. Neste sentido, adquire significado especial a referência às estrelas e ao firmamento, indiciados já no título do 
romance e transformados em objeto de interesse e de fascínio de Jorge, justamente o prisioneiro que, de forma mais brutal, sofre a violência da cadeia:

"[...] vou até a janela da sala, fico a admirar o céu estrelado, aos poucos e poucos perco o medo" (p.180).

Para ele, olhar para o céu e aprender sobre as constelações é artifício de libertação e de beleza, possibilidade maior de evasão, jogo possível para, ao mesmo tempo, invenção de outra realidade e reflexão sobre a condi- ção humana, sintetizada ali em condição carcerária, representada pelas sete personagens recortadas pelo autor, que se transformam, pelo olhar do companheiro mais jovem, nas sete estrelas da Ursamaior. Tal transformação abre ao leitor múltiplas possibilidades de interpretação e confirma a originalidade da instigante proposta ficcional de Mário Cláudio, garantindo, mais uma vez, o lugar de excelência ocupado por sua produção no panorama da narrativa portuguesa contemporânea. 